\title{
Número Especial \\ Derecho a la Educación e Inclusión Escolar de Jóvenes LGTB+ en América Latina y el Caribe
}

\section{archivos analíticos de políticas educativas}

Revista académica evaluada por pares, independiente, de acceso abierto y multilingüe

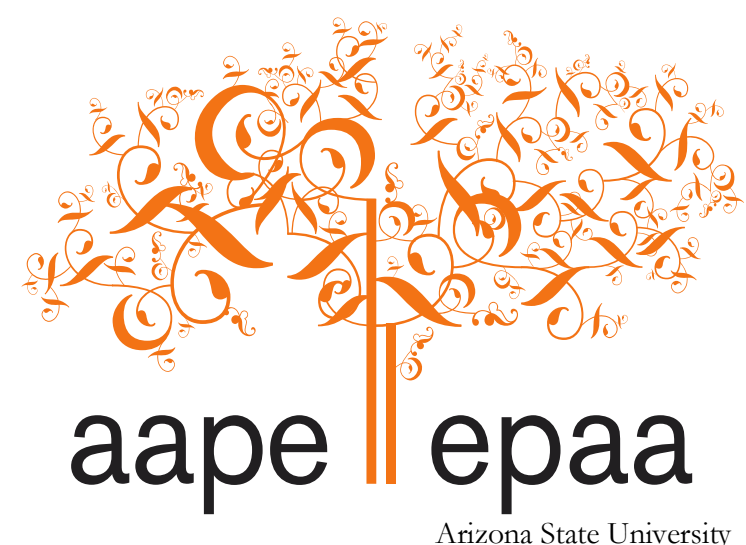

\section{Una Aceptación Silenciosa: Actitudes de Profesores en Torno a la Diversidad por Orientación Sexual, Identidad y Expresión de Género (OSIEG) en Chile}

\author{
Pablo Astudillo Lizama \\ Universidad Alberto Hurtado \\ Chile \\ \&o \\ Rocio Faúndez García \\ Fundación Todo Mejora \\ Chile
}

Citación: Astudillo, P., \& Faúndez, R. (2021). Una aceptación silenciosa: Actitudes de profesores en torno a la diversidad por orientación sexual, identidad y expresión de género (OSIEG) en Chile. Archivos Analíticos de Políticas Educativas, 29(142). https://doi.org/10.14507/epaa.29.5907 Este artículo forma parte del número especial, Derecho a la Educación e Inclusión Escolar de Jóvenes LGTB+ en América Latina y el Caribe, editado por Jaime Barrientos Delgado, María Teresa Rojas, Ismael Tabilo Prieto y Canela Bodenhofer.

Resumen: Las actitudes docentes se pueden definir como "aquellos valores y normas intrínsecas de los sujetos que dirigen su quehacer profesional, en relación con los procesos pedagógicos" (Maturana et al., 2016). Estas podrían ser entendidas a partir de al menos tres factores que interactúan entre sí: la lectura de las normas sociales que impactan los procesos educativos, lo aprendido durante la formación inicial docente y la adecuación de los individuos a las culturas organizacionales de los lugares de trabajo donde se desempeñan. Teniendo esto a la vista, el presente 
artículo presenta los resultados de un estudio sobre actitudes de profesores en torno a la diversidad por orientación sexual, identidad y expresión de género (OSIEG) en Chile, atendiendo además a otros elementos diferenciadores individuales que pueden influir en la manera como las actitudes docentes toman forma en el ejercicio profesional: género, trayectoria y geocultura. A partir del análisis de veinte entrevistas realizadas a docentes en tres ciudades del país (Santiago, Valparaíso y Talca) además de una revisión de 132 mallas curriculares de programas de formación en pedagogía en las tres regiones observadas, se llega a la conclusión que los docentes tienen una actitud favorable hacia la diversidad por OSIEG, aunque aquella disposición no se traduce en una modificación del quehacer profesional, de los procesos pedagógicos o el cuestionamiento de la política educativa. Esta aceptación silenciosa ofrece, por lo tanto, oportunidades y limitaciones para avanzar en la reflexión sobre la inclusión. En estas condiciones, por tanto, es todavía difícil cuestionar el modo cómo la norma de género y sexualidad es reproducida y producida constantemente por las escuelas en Chile. Palabras clave: Docentes; competencia profesional; formación de docentes; educación; género; sexualidad

\section{A silent acceptance: Teachers' attitudes towards sexual orientation, gender identity and expression (SOGIE) diversity in Chile}

Abstract: Teachers' attitudes can be defined as "those intrinsic values and norms of subjects that direct their professional work, in relation to pedagogical processes" (Maturana et al., 2016). At least three factors are at play in the shaping of such attitudes: the perception of social norms that impact educational processes, what was learned during initial teacher training, and the adaptation of individuals to the organizational cultures of the workplace. Bearing this in mind, this article presents the results of a study on teachers' attitudes towards diversity by sexual orientation, gender identity and expression (SOGIE) in Chile, also taking into account other individual differentiating elements that may influence the way attitudes take shape in professional practice: gender, trajectory and geoculture. From the analysis of twenty interviews conducted with teachers in three cities of the country (Santiago, Valparaíso and Talca) as well as a review of 132 curricular networks of pedagogy training programs in the three observed regions, it is concluded that, while teachers do have a favorable attitude towards diversity by SOGIE, it does not translate into a modification of professional work, pedagogical processes or questioning of educational policy. This silent acceptance therefore offers opportunities and limitations to advance the reflection on inclusion. Under these conditions, it is still difficult for the way in which schools constantly produce and reproduce norms that regulate gender and sexuality to be questioned in Chile

Keywords: Teachers; professional skills; teacher training; education; gender; sexuality

\section{Uma aceitação silenciosa: Atitudes dos professores em relação à diversidade de orientação sexual, identidade e expressão de gênero (OSIEG) no Chile}

Resumo: As atitudes docentes podem ser definidas como "aqueles valores e normas intrínsecas dos sujeitos que direcionam o seu trabalho profissional, em relação aos processos pedagógicos" (Maturana et al., 2016). Isso poderia ser entendido a partir de pelo menos três fatores que interagem entre si: a leitura das normas sociais que impactam os processos educacionais, o que foi aprendido durante a formação inicial de professores e a adaptação dos indivíduos às culturas organizacionais do local de trabalho. Tendo isso em mente, este artigo apresenta os resultados de um estudo sobre as atitudes de professores em relação à diversidade por orientação sexual, identidade e expressão de gênero (OSIEG) no Chile, também levando em consideração outros elementos diferenciadores individuais que podem influenciar a forma como as atitudes docentes se configuram na prática profissional: gênero, trajetória e geocultura. A partir da análise de vinte entrevistas realizadas com professores em três cidades do país (Santiago, Valparaíso e Talca), bem como de uma revisão de 132 
matrizes curriculares de programas de formação em pedagogia nas três regiões observadas, concluise que os professores têm um perfil favorável de atitude perante a diversidade OSIEG, embora essa disposição não se traduza em modificação do trabalho profissional, processos pedagógicos ou questionamento da política educacional. Esta aceitação silenciosa, portanto, oferece oportunidades e limitações para avançar na reflexão sobre a inclusão. Nessas condições, portanto, ainda é difícil formular um julgamento a maneira como a norma de gênero e sexualidade é constantemente reproduzida e produzida pelas escolas chilenas.

Palavras chave: Professores; competência profissional; formação de profesores; educação; gênero, sexualidade

\section{Una Aceptación Silenciosa: Actitudes de Profesores en Torno a la Diversidad por Orientación Sexual, Identidad y Expresión de Género (OSIEG) en Chile}

Diferentes estudios desarrollados en Chile señalan que los establecimientos escolares del país seguirían siendo un "espacio inseguro" para los estudiantes. Esto, a consecuencia de la facilidad con la que dentro de ella siguen circulando comentarios negativos basados en la orientación sexual e identidad de género, tanto entre estudiantes como también por parte del personal adulto del establecimiento, incluidos los docentes (Cáceres y Salazar, 2013; INDH, 2017; Kosciw y Zongrone, 2019; Rojas et. al 2019; Todo Mejora, 2016.)

Lo anterior no deja de ser llamativo si se considera que el país ha experimentado una mayor aceptación de la diversidad sexual en años recientes lo que se traduciría en una menor adhesión a discursos públicos de discriminación, los cuales incluso podrían ser sancionados por ley (Barrientos, 2015). Sumado a lo anterior, la política educativa reciente ha dado pie a orientaciones y normativas que precisamente buscan evitar todo este tipo de discriminaciones, ya sea a través de la Ley de Inclusión Escolar de 2015 o la Circular N0768 de la Superintendencia de Educación "Derechos de niños, niñas y estudiantes trans en el ámbito de la educación” y las "Orientaciones para la Inclusión de las personas lesbianas, gays, bisexuales, trans e intersex en el Sistema Educativo" del año 2016, instrumentos que a priori buscan hacer cumplir el derecho a la educación de este colectivo en un ambiente libre de menoscabo (Rojas et al. 2019). En tal contexto cabe hacerse la pregunta respecto a qué factores mantienen esta situación de inseguridad para ciertos estudiantes y hacen que la norma política no necesariamente se traduzca en un cambio de comportamiento dentro del espacio escolar.

En paralelo, responder a esta interrogante permite entrar en los debates en torno a la justicia social y educativa, los cuales han puesto el acento en las operaciones sociales que permiten que cada individuo tenga seguridad de ser reconocido por otro en igualdad de condiciones (Fraser, 2008; Connell, 2006; Fraser y Honneth, 2006). En el caso de la escuela, este reconocimiento es algo que puede estar asegurado formalmente mediante leyes, normas u orientaciones que regulan el currículo y la convivencia escolar, pero no necesariamente por las interacciones que tienen lugar dentro de ella, donde siguen existiendo asimetrías visibles respecto de los estudiantes que tensionan las normas de género y sexualidad (Connell, 2002, 2015). En tal caso, las posibilidades reales que tienen los sujetos de participar en las decisiones que les competen es limitada, haciendo difícil su inclusión escolar o su participación en el proceso educativo (Miller, 2016).

Los actores que participan del fenómeno que acabamos de describir son múltiples. En el caso de este estudio, nos concentraremos en los docentes, específicamente en sus actitudes en torno a la diversidad por orientación sexual, identidad y expresión de género (OSIEG). De este modo podemos atender a su posición como facilitadores u obstaculizadores para reducir la ambigüedad entre norma política y práctica cotidiana, y a su capacidad de convertir las escuelas en espacios más seguros para todo el estudiantado sin distinción. Para ello, entenderemos actitudes docentes como 
"aquellos valores y normas intrínsecas de los sujetos que dirigen su quehacer profesional, en relación con los procesos pedagógicos" (Maturana et al., 2016); es decir, nos referiremos a ciertos elementos de su subjetividad personal que predisponen un determinado modo de actuar en la materia. A partir de tal definición podremos avanzar en aquellos aspectos que, en una escala individual, explican en parte este fenómeno social.

\section{Marco de Referencia}

\section{Las Normas Sociales sobre Género y Sexualidad}

Lo que ocurre en las escuelas no puede ser entendido fuera del contexto social donde ellas operan. En Occidente, el género y la sexualidad funcionan como sistemas normativos y epistemológicos, donde la distinción anatómica entre los cuerpos se asocia a una serie de expectativas culturales que recaen sobre el deseo y el comportamiento sexual de los sujetos (Connell, 2002; Laqueur, 1994; Rubin, 1984). Estas normas orientan la acción y juicio de los individuos, al tiempo que le asignan una posición dentro de una estructura de poder y acceso a recursos materiales y simbólicos (Bourdieu, 2000; Connell 2002; Connell \& Pearse, 2018; Rubin, 1984; Scott, 1990). Al mismo tiempo, tienen la capacidad de infiltrar la vida social al punto de ser consideradas como naturales y obvias para los sujetos (Connell, 2002), sin comprender como su reproducción corresponde a una construcción política (Butler, 1990). Como resultado, todo aquello que cumple la norma es sujeto de privilegio, mientras que todo aquello que no la cumple es sistemáticamente objeto de sospecha, sanción y subordinación, especialmente, en sociedades como la nuestra donde la cisheterosexualidad es posicionada como un ordenamiento superior a cualquier otra forma de organizar el comportamiento sexual (Butler, 1990; Wittig, 1980).

Luego, al entender las normas como un sistema de significados culturales que dan forma a medios de control social pero también a modos de autorregulación y agencia (Dubet, 2010), se comprende que ningún individuo se ubica por fuera de aquellas. Lo fundamental radica en el posicionamiento de los sujetos en conformidad a las prescripciones sobre el género y el sexo, la manera como esto produce una subjetividad y una forma de entender la diferencia entre los individuos. En este sentido, la escuela, como institución que fabrica individuos sociales y morales (Dubet, 2010), replica la desigualdad de los sujetos frente a la norma que privilegia la cisheterosexualidad, mediante la circulación de discursos denigratorios como también por la falta de reconocimiento de la diversidad sexual y de género en el currículo formal (Miller, 2016; Rojas et al. 2019). De este modo, las identidades que tensionan la norma siguen siendo presentadas como ilegítimas en comparación a la cisheterosexualidad. Si bien en la mayoría de los casos ya no existe formalmente un discurso que sancione la diferencia, se constata que en las escuelas las situaciones de discriminación son persistentemente invisibilizadas al tiempo que las identidades de género y orientaciones sexuales diversas pocas veces son presentadas con claridad ante los estudiantes, es decir, no son inteligibles dentro de la escuela (Staunton, 2020). Al mismo tiempo, dentro de los establecimientos no se ha tomado conciencia de cómo los espacios siguen estando segmentados: mientras en las aulas se pueden movilizar discursos de inclusión, los baños, camarines o patios siguen siendo lugares donde subsiste la violencia homofóbica y transfóbica, todo lo cual expone a los estudiantes que tensionan la norma a no ver satisfecho su derecho a la educación (Barrientos et al., 2020; Kosciw y Zongrone, 2019; Miller, 2016; Rojas et al., 2019; Staunton, 2020). En este contexto, el actuar de los docentes es crucial, pues aquellos poseen un poder concreto para quebrar estas tendencias en virtud de su capacidad de movilizar conocimientos y de su autoridad en términos disciplinarios (Maturana et al., 2016; Staunton, 2020). 
Ahora bien, en relación con la aceptación de la diversidad por orientación sexual, identidad y expresión de género, un elemento adicional debería ser tenido en cuenta: el creciente escrutinio al cual está sometido la sexualidad personal de los docentes. En el contexto de las sociedades occidentales, la sexualidad está sometida a una norma de coherencia personal, en la medida que, ante el declive del poder regulador de las instituciones, los sujetos están conminados a organizar individualmente su comportamiento sexual (Bozon, 2009). Al mismo tiempo, deben ser capaces de argumentar las decisiones que toman, pues la sexualidad crecientemente es entendida como la expresión más importante de la intimidad personal y de allí que el comportamiento individual sea revelador de la calidad moral de los sujetos (Giddens, 1992). En el caso de los docentes, esto tiene consecuencias específicas, pues dicha norma opera en conjunto con una expectativa social que espera que el profesor sea un profesional desexualizado (Connell, 2015; Neary, 2017). En este sentido podemos suponer que cuando los docentes hablan sobre sexualidad y género, piensan que también están diciendo algo sobre su propia interioridad por lo que constantemente habrá que definir la propia postura personal y su ubicación respecto de las normas sociales sobre sexualidad y género.

Considerando esto, identificamos dos dimensiones adicionales que permiten aproximarse al fenómeno que queremos estudiar. En primer lugar, el modo como las normas sobre género y sexualidad son transmitidas a los sujetos en la escuela, con especial énfasis en la educación sexual y la formación inicial docente sobre estos temas. En segundo lugar, la manera como la escuela -en tanto lugar de desenvolvimiento cotidiano- actúa como bisagra entre la sociedad y el individuo, reduciendo o acrecentando la distancia entre normas sociales y posturas personales. De este modo es posible tener una aproximación más exacta a las actitudes docentes, aquellos valores y normas intrínsecas que guían su actuar profesional frente a la diversidad.

\section{El Currículo sobre Sexualidad y Género}

Cuando se piensa en la inclusión de la diversidad por orientación sexual, identidad y expresión de género, necesariamente operan distinciones formales presentes en los programas de educación sexual, manuales de convivencia y normativas de diverso tipo. Tales distinciones son siempre el resultado de una traducción escrita de determinadas normas sociales, las cuales a su vez son consecuencia de una manera específica de entender el género y la sexualidad en un espacio social determinado (Morgade, 2016).

Para analizar la educación sexual en Chile el primer elemento que debería ser considerado es la inexistencia de un currículo formal único en esta materia. La Ley 20.418 ("Fija Normas sobre Información, Orientación y Prestaciones en Materia de Regulación de la Fertilidad") es aquella que regula la materia en la actualidad. Dicha norma cautela que no se impongan visiones y currículos totalizantes; esto, en la medida que se entiende que cualquier propuesta en la materia no puede sobrepasar el principio constitucional de libertad de enseñanza, donde siempre las escuelas deberán cautelar el derecho a elegir de los padres (Figueroa, 2012). Como resultado, la educación sexual se organiza a partir de un principio de competencia, donde oferentes privados (fundaciones,

organismos eclesiales, profesionales independientes) promueven alternativas que las escuelas pueden elegir y donde los conocimientos sobre género y sexualidad son presentados asumiendo los sesgos valóricos que cada una de estas propuestas conlleva (Palma et al., 2013). En este sentido, dentro del sistema escolar coexisten formas de hablar sobre sexualidad que varían profundamente en cuanto a sus contenidos, métodos de enseñanza y formas de tematizar normas sociales a veces contrapuestas como pueden ser los valores religiosos y las evidencias científicas (Figueroa, 2012).

Lo anterior necesariamente genera un escenario donde la transmisión de contenidos sobre sexualidad y género se personaliza, pues obliga a los sujetos a tomar postura individual sobre ciertas normas y procedimientos respecto de los cuales no existe consenso social. A nivel didáctico, esto también acarrea consecuencias: en Chile, y tal como lo demuestra un estudio realizado por 
UNESCO en 2019, los procesos de planificación e implementación didáctica realizados a partir de las Orientaciones Técnicas Internacionales sobre Educación en Sexualidad tienden a ser discrecionales, estableciéndose planes de educación sexual con definiciones laxas, que dan pie a transferencias de creencias personales de los docentes, las que tienden a ser normalizadoras en vez de reflexivas. La falta de un marco conceptual y valórico explícito sobre la sexualidad, a juicio del informe, redunda en que la educación sexual sea siempre vista como un acto improvisado (UNESCO, 2019, p. 25).

Podemos agregar que la centralidad asignada al individuo, a su capacidad de elección y a la posibilidad de resolver "problemas concretos" en relación con la educación sexual, limita también las posibilidades de comprensión de otros elementos sociales que enmarcan la sexualidad y el género, como podrían ser la relación entre clase social y expresión de la sexualidad, la relación entre género y comportamiento sexual, o la producción social de las ideas de normalidad y diferencia que se desprenden de estos cruces entre marcadores sociales (Collins y Bilge, 2016). A modo de ejemplo, el "buen trato" hacia la diversidad de género y sexualidad que se observa en determinadas escuelas de élite, estaría sustentado en una comprensión paternalista y acrítica de la diferencia, donde la norma nunca es construida participativamente por los sujetos a las cuales afecta (Astudillo, 2016). Este último factor es relevante, toda vez que la educación supone concepciones de la normalidad que no están tematizadas a pesar de su carácter político y contingente, cuestión que no solo atraviesa la institución escolar sino también aquellas que forman profesores (Ferguson, 2018; Matus e Infante, 2011).

Por esta razón, las actitudes deberían ser examinadas también en relación con la formación inicial docente, en la medida que esta última no solo está moldeada por determinados valores formales, sino que también predispone expectativas sobre la profesión (Fernández, 2018; Stolze y Ramírez, 2015). El aprendizaje de la profesión supone la prescripción de un rol; sin embargo, dicho rol se pone siempre en tensión al momento de ejercer profesionalmente. Los docentes, en este sentido, están conminados a encontrar los puntos de encuentro y diferenciación entre teoria y práctica, entre formación y desempeño profesional. En el caso específico de la diversidad por orientación sexual, identidad y expresión de género, lo anterior se relaciona también con las necesidades que los docentes reconocen en el aula y en los distintos encuentros sociales que ocurren en las escuelas. En tal caso se reconoce la necesidad de un aprendizaje específico de contenidos y evidencias científicas que pueden ser luego movilizadas en los procesos educativos. En los espacios universitarios nacionales estas transferencias todavía no se desarrollan en plenitud (Maturana et al., 2016; Salas y Salas, 2016).

\section{Un Reconocimiento de la Agencia Individual dentro de una Cultura Organizacional}

François Dubet y Danilo Martuccelli (1996) sostienen que la institución escolar fabrica los actores sociales que componen una sociedad cualquiera; esto, a partir de la institucionalización de un currículo y de la elección de métodos con los que se busca acercar a los individuos a un ideal de sujeto. Desde este punto de vista, la escuela materializa un ideal ético. Sin embargo, dentro de ella los individuos no aprenden simple y linealmente este rol prescrito institucionalmente, pues el ideal de sujeto también se construye a partir del encuentro dinámico entre estudiantes, profesores, directivos, padres y personal de apoyo escolar. Tales interacciones dan forma a un currículo oculto donde, mediante el humor, los juegos, las formas de autoridad y otras prácticas, se estabilizan discursos que pueden potenciar o contradecir la norma escrita, al constituirse también como un régimen de verdad que orienta la acción de los sujetos. Considerando esto, los autores afirman que el análisis de los fenómenos escolares debiera incluir tanto los aspectos formales del currículo como también las interacciones que se desarrollan en la escuela, pues ambos aspectos producen y reproducen las normas sociales. 
Por esta razón, al análisis de la formación en sexualidad debiera añadirse también la relación que los docentes tienen con el currículo oculto de su lugar de trabajo. Esto, porque dicha estructura normativa, al igual que en el caso del currículo formal, tiene consecuencias en los procesos de diferenciación e identificación social. En otras palabras, tanto la instrucción como la socialización tienen efectos sobre cómo los individuos en la escuela van a entenderse a sí mismos. En el caso específico que nos convoca, el currículo oculto tiene la particularidad de jerarquizar los comportamientos dentro del espacio social escolar, asignando distintas representaciones y posibilidades de agencia personal a los individuos en función de su orientación sexual, identidad y expresión de género, tensionando necesariamente la idea de que la escuela "no hace distinciones" entre los sujetos (Barrientos et al., 2020; Renold, 2004; Rojas et al., 2019).

Desde el punto de vista del quehacer docente, ejemplos hay varios. Zoé Rollin (2012) afirma que la forma de actuar de los y las profesoras con relación a la aplicación de disciplina y la expresión del cuidado personal tiende a ser estructurada en función del género (la autoridad a lo masculino, la ternura a lo femenino), teniendo consecuencias concretas en los alumnos durante la construcción de su propia identidad personal. Autoras como Catherine Marry (2004), Marie Duru-Bellat (2008) y Beatrix Niemeyer y Helen Colley (2015) por su parte, identifican cómo en las escuelas, los profesores van estabilizando ciertas ideas de género, al privilegiar en términos de atención y refuerzos a hombres y mujeres distintamente según la disciplina que se observe, con consecuencias sobre las elecciones disciplinarias que los estudiantes realizarán a futuro (matemáticas y ciencias para los hombres; lenguaje y cuidado para las mujeres) y la naturalización de que los sujetos tienen capacidades diferentes según su sexo biológico.

En el caso de la orientación sexual, la situación es similar. Los profesores tienen un rol activo en la mantención de la violencia homo/lesbo/bifóbica en la medida que la vigilancia sobre la misma tiende a ser laxa cuando se considera que son solo "bromas propias de los estudiantes" normalizando la orientación heterosexual del deseo (Barrientos et al., 2020; Cáceres y Salazar, 2013; Romero et al., 2005) Al mismo tiempo, las prácticas docentes tienden a establecer normas sobre el cuerpo sexuado, estabilizando asociaciones entre sexo y género, lo cual sirve de base para el despliegue de la violencia transfóbica en la escuela (Catalán, 2018; Morgade, 2008), esto, en la medida que las acciones pedagógicas sobre género y sexualidad necesariamente están cruzadas por la experiencia personal de los profesores, altamente influenciadas por un sistema cisheteronormativo (Cumming-Potvin y Martino, 2018; Wei, 2020; Youdell, 2005). Considerando el contexto internacional esto resulta ser una constante: por ejemplo, en el caso de los países escandinavos o de Escocia, el currículo y los documentos oficiales del sistema escolar han incorporado los conceptos de orientación sexual, expresión de género, identidad de género o identidades no binarias como reconocimiento de la diversidad sexual (Kjaran \& Lehtonen, 2017), mientras que organismos como la UNESCO han fomentado que el currículo escolar otorgue visibilidad y relevancia a los derechos humanos en el ámbito de la diversidad sexual (Unesco, 2016). Sin embargo, aún en estos casos, la investigación reporta dificultades para implementar una agenda de inclusión, justicia social y respeto a la diversidad sexual en las escuelas en la medida que la práctica de los individuos tiende a contradecir la norma escrita (Bragg et al 2018; Cumming \& Martino, 2018; Ferfolja \& Ullman, 2017; Kosciw \& Zongrone, 2019).

En este sentido el quehacer docente tiene una importancia estratégica por su capacidad de reforzar y sancionar los comportamientos de los estudiantes, profundizando o cuestionando las normas del currículo oculto (Devis et al., 2005). Ahora bien, dicho currículo es siempre situado, pues está en directa relación con los valores y formas de distinción social presentes en una escuela (Draelants y Dumet, 2011; Dubet y Martuccelli, 1996). Por esa misma razón, deberíamos considerar la relación entre actitudes y la cultura organizacional donde se desenvuelve el docente. Si consideramos además que las escuelas no siempre delimitan de la misma manera la frontera entre lo público y lo privado, tendremos por 
resultado que el ajuste entre los propios valores y el propio comportamiento finalmente desarrollado en la escuela puede variar enormemente de individuo en individuo (Rollin, 2012; Catalán, 2018).

\section{Las Actitudes Docentes y la Diversidad por Orientación Sexual, Identidad y Expresión de Género}

Considerando lo anterior, el principio orientador de este estudio es el siguiente: que las actitudes de los docentes están relacionadas con el modo como el sujeto se posiciona con relación a los valores sociales sobre diversidad en materia de sexualidad y género, a los contenidos transmitidos durante su propia formación docente y a las culturas organizacionales del lugar donde se desenvuelve profesionalmente. En este sentido se asume que el docente es un agente activo, que realiza elecciones estratégicas permanentemente, que puede identificarse o criticar un determinado principio valórico que circula en su entorno, y que resuelve permanentemente las tensiones normativas a las cuales se ve enfrentado, construyendo de esta manera una subjetividad personal (Araujo, 2009; Dubet, 2010) circunscrita en este caso a la diversidad por orientación sexual, identidad y expresión de género.

Ahora bien, independientemente de la variabilidad de las normas sociales, currículos de formación inicial docente y culturas organizacionales que enfrenta un docente, asumimos que existen también otros factores que pueden incidir en cómo se desarrolla este proceso. Nos referimos a cuestiones tales como el género y edad del individuo (los cuales pueden definir trayectorias vitales diferentes y con ello una construcción diferenciada de valores y prejuicios), el género o la orientación sexual del mismo (que nos haría suponer una posición específica respecto a las desigualdades sociales que surgen de estos criterios), la observancia religiosa (que implica la adherencia a proyectos éticos específicos que impactan las normas con las que se evalúa la sexualidad de los individuos) o las experiencias previas en relación con la diversidad (que se puede asociar con aprendizajes y estrategias personales para enfrentar la cuestión), todas las cuales -entre otras- pueden incidir en las actitudes de los sujetos. Por ello, la atención a las biografías y trayectorias personales es crucial, para así recuperar la variabilidad de los procesos individuales, la manera como los sujetos explican sus estrategias y la posición que se autoasignan dentro del sistema social (Dubet, 2010; Singly, 2010).

\section{Método}

El énfasis del estudio estuvo puesto en las narrativas que movilizan los docentes al momento de describir sus actitudes hacia la diversidad por orientación sexual, identidad y expresión de género (OSIEG) en el contexto escolar. Para ello se consideraron las percepciones personales de las normas sociales que actualmente regulan la diversidad en general y la diversidad por OSIEG en particular, la opinión frente a la formación inicial docente recibida y el modo como se entiende la cultura organizacional del propio lugar de trabajo. Al mismo tiempo, se indagó en las estrategias personales que los docentes desarrollan para enfrentar cualquiera de estas materias. Toda esta información se obtuvo a través de la realización de 20 entrevistas semiestructuradas las cuales fueron analizadas siguiendo una metodología de análisis de discurso, que codificó la información recopilada a partir de las tres dimensiones previamente definidas y que a partir de la comparación permanente de casos generó nuevos códigos analíticos que permitieron establecer relaciones entre los hallazgos.

En términos muestrales, se adoptó un diseño basado en cuotas, con el fin de asegurar una variabilidad de casos en torno a tres variables principales: género, trayectoria (profesores en práctica profesional, con 2 y con 6 o más años de ejercicio) y geocultura (Santiago, la capital nacional; Valparaíso, tercera área metropolitana del país; y Talca, capital regional de tamaño medio). La dependencia institucional y la confesionalidad de la escuela a la cual adscriben los entrevistados no 
fueron criterios para definir cuotas, sin embargo, se procuró en lo posible contar con casos que permitieran también observar diferencias en este sentido. De este modo, y aumentando los criterios de búsqueda para sucesivos casos, se buscó la mayor heterogeneidad de casos, sin necesariamente plantear una representatividad estadística. El siguiente cuadro resumen muestra la distribución final de casos:

\section{Tabla 1}

Distribución de los Casos Muestrales

\begin{tabular}{|l|l|l|l|l|l|l|l|l|}
\hline & \multicolumn{2}{|l|}{ Santiago } & \multicolumn{2}{l|}{ Valparaíso } & \multicolumn{2}{l|}{ Talca } & Total \\
\hline Género & M & F & M & F & M & F & \\
\hline Practicante profesional de pedagogía & 2 & 1 & 0 & 1 & 1 & 1 & 6 \\
\hline Profesores con 2 años de ejercicio & 1 & 1 & 1 & 1 & 1 & 1 & 6 \\
\hline Profesores con 6 o más años de ejercicio & 2 & 2 & 1 & 1 & 1 & 1 & 8 \\
\hline Total & 9 & 5 & & 6 & & 20 \\
\hline
\end{tabular}

Fuente: elaboración propia

En cuanto a la caracterización de la muestra, respecto de las disciplinas a las que adscriben los profesores, 12 casos correspondían a pedagogías en Filosofía, Matemáticas y Educación General Básica (4 casos cada una), seguidos de Lenguaje y Comunicación (3 casos), Inglés (2 casos), Historia, Música y Biología (1 caso cada uno). También es necesario señalar que, dado el procedimiento de muestreo, las personas que aceptaron ser parte del estudio correspondieron a sujetos que presentan algún grado de afinidad con la temática de investigación, en el sentido que no expresan un rechazo abierto a hablar sobre diversidad sexual y de género; por lo que puede haber cierto sesgo de autoselección. Cabe señalar que, a pesar de no haber sido establecido como un criterio de muestreo, dos docentes se presentaron ante el equipo investigador como no heterosexuales (lesbiana y gay), lo cual enriquece el análisis en determinados puntos. En este sentido, aunque el foco de las entrevistas estuvo puesto en las narrativas y comportamientos personales, la constante referencia a las actitudes de otros profesores en el entorno escolar permitió contar con una multiplicidad de puntos de vista que ayudó en la interpretación de los datos recopilados.

Por último, y como una manera de complementar la información respecto a la formación inicial docente se realizó un análisis de 132 mallas curriculares de todas las carreras de pedagogía dictadas en las tres regiones donde se realizaron las entrevistas a docentes (Región Metropolitana, del Maule y de Valparaíso). A partir de la información disponible en páginas web, y de lo referido por los docentes en las entrevistas, se buscó la presencia o ausencia de dos tipos de cursos en particular: los relativos al desarrollo psicológico de niños y adolescentes y los relacionados con materias de diversidad y educación. De todos modos, es importante señalar que este análisis no consideró cursos electivos, por dos razones: uno, porque esta información difícilmente está publicada en las mallas curriculares (en virtud de su variabilidad semestral) y segundo, porque no corresponden a la formación obligatoria y por ende no pueden extrapolarse al conjunto de profesores en formación.

\section{Principales Hallazgos}

\section{La Transformación de las Normas Sociales}

Los entrevistados, en distintos momentos, aluden a que en el país "las cosas han cambiado": la diversidad sexual y de género deja de ser un tema tabú, algo consistente con los hallazgos de Jaime Barrientos (2015) a propósito de la violencia homofóbica en Chile. En las escuelas, las orientaciones sexuales y expresiones no tradicionales del género serían hoy más visibles, desarrollándose frente a 
ellas una disposición de aceptación relativa. La abierta violencia, física o psicológica, ya no sería aprobada como antes, lo cual habría permitido que los estudiantes LGBTI ${ }^{1}$ puedan "salir del clóset" en los establecimientos, al mismo tiempo que se han visibilizado las parejas del mismo sexo. En paralelo, los cambios que ha vivido la sociedad chilena han posibilitado que los estudiantes expresen su identidad individual utilizando estrategias tradicionalmente asociadas a otro género (hombres que se pintan las uñas, mujeres que utilizan el pelo corto), todo lo cual se atribuye a un cambio cultural generalizado en el país que se reproduce dentro de la escuela. No obstante, todavía persisten algunas resistencias pues el cambio está aún en curso.

En Chile estamos recién cambiando algunas conductas que son de tendencia más machista. Bueno en mi caso, yo soy más viejo, nos inculcaban esto 'los hombres no lloran', 'los hombres usan pantalones', 'no se pintan', 'no se tiñen'. (...) Entonces cuando alguien se sale un poco de esos parámetros, a lo mejor en la forma de gesticular, de hablar y de vestirse hace que uno se confunda. Fijate, yo también caí una vez. Fui a misionar y vi un joven que se vestía así bien femenino, y yo pensé que este tipo era gay; y no, tenía polola y toda la cuestión. O sea, es así. Todavía nos falta cambiar esa parte. (profesor, Valparaíso, más de seis años de experiencia)

Los entrevistados relacionan este cambio normativo con la mayor visibilidad que la diversidad sexual ha adquirido en los medios de comunicación y a la actitud de mayor apertura a la sexualidad y a expresiones de género diversas que muestran las generaciones más jóvenes. En este sentido, los docentes de mayor edad son quienes más claramente ejemplifican estos cambios, pues su trayectoria personal les permite hacer comparaciones sustantivas. Por ejemplo, se identifica como punto de inflexión al crimen de Daniel Zamudio en el año 2012, el cual ha favorecido una mayor aceptación, a nivel cultural, de la homosexualidad en Chile. También los profesores mayores y utilizan con mayor frecuencia la palabra "tabú" para referirse a la inexistencia, durante su juventud, de discursos sobre la sexualidad en general y la homosexualidad o las identidades trans en particular. Sin embargo, a partir de los datos del estudio, no es posible establecer con claridad cuál es la frontera etaria que separa un grupo del otro, pues a veces los profesores practicantes (con edades que no superan los 24 años) presentan a los estudiantes como "los jóvenes" sin necesariamente problematizar la corta diferencia en años que existe entre ellos. Esto hace suponer que el factor más relevante para organizar los discursos es la posición como actor dentro del sistema escolar más que su edad propiamente tal.

Ahora bien, este cambio normativo no implica necesariamente la eliminación de toda forma de discriminación, sino más bien un desplazamiento de las formas de rechazo (Barrientos, 2015). Dentro de las escuelas todavía subsisten formas de violencia simbólica asociadas sobre todo al posicionamiento de los estudiantes LGBTI+ o aquellos que siendo cisheterosexuales no se ajustan a la expresión de género tradicional. Esto se observa en la persistencia de descalificaciones relacionadas con el uso peyorativo de las palabras "maricón", "fleto", "loca" o "camiona" las cuales funcionan como una forma de inferiorización de los individuos no heterosexuales cisgénero o con expresiones de género no heteronormadas. Estas burlas son movilizadas por los mismos estudiantes;

\footnotetext{
${ }^{1}$ Si bien en este artículo utilizamos la noción de diversidad por orientación sexual, identidad y expresión de género (OSIEG), reproducimos acá la expresión LGBTI+ para agrupar las distintas identidades a las cuales hacen referencia los docentes participantes de este estudio (lesbianas, gays, bisexuales, trans), validando un acrónimo utilizado por organizaciones internacionales y por la bibliografía consultada y donde el signo + simboliza la imposibilidad de cerrar y delimitar las identidades sexuales y de género. De todos modos, resulta interesante constatar que tanto la I (intersex) como como el + no son mencionados ni problematizados por los participantes del estudio, lo que viene a corroborar su invisibilidad dentro de los discursos sobre diversidad sexual y de género dentro de las escuelas chilenas (Rojas et. Al., 2019)
} 
o bien por los docentes que -aduciendo la "censura" que impone la nueva "corrección política"restringen su circulación a espacios privados como reuniones o conversaciones en la sala de profesores. Esta forma de violencia también se manifiesta en el discurso de los docentes que presentan a los estudiantes que tensionan la norma como sujetos que se victimizan innecesariamente o que atraen la atención de manera inadecuada.

Resulta interesante que la gran mayoría de los entrevistados identifiquen claramente esta ambivalencia, sintetizada también en la idea que "las cosas han cambiado, pero los homosexuales todavía tienen miedo de expresarse libremente en la calle", "un profesor homosexual tendría graves problemas para ejercer la profesión", o "estas son cosas que no se pueden hablar con los niños", esto, a pesar de que la ley Antidiscriminación del 2012 supondría una protección ante tal menoscabo.

Si yo tuviera que decirle a un extranjero homosexual que viene con su pareja, yo le diría no lo hagan [se refiere a andar de la mano en la calle]. Yo siento que en Chile la gente sabe que existen, dice que está bien, pero "mientras no sea en el patio de mi casa" o "no mientras mis hijos te vean". Está mucho esto de que, si se da libertad a la gente transgénero, como que se está promoviendo que la gente sea transgénero. No se entiende que al final es una cuestión interna de cada persona y no es algo de marketing. (profesor practicante, Santiago)

Profesionalmente considero que es un tema que se debe abordar, pero no sé si con chicos tan pequeños para serte sincera, ósea me contradigo sola porque tuve el caso de un niño que lo discriminaban y que me afectó bastante, pero no sé si el día de mañana hablándote como mamá me gustaría que en kínder de mi hija le hablaran de esto. (profesora en práctica, Talca)

Hace poco vi complicada a una niña. Yo le pregunto qué le pasaba y ella me dijo que estaba sintiéndose confundida con respecto a lo que le gustaba y lo que no le gustaba. Se supone que yo debería haberle avisado a la inspectora, luego a la psicóloga, para que conversaran con la niña. Pero yo sentía que, si pasaba eso, iban a invadir la privacidad de la niña y que las herramientas con que cuentan ellas no iban a ser las óptimas. Entonces, preferí abordar yo el tema; conversar con la niña y explicarle que esto era propiamente de la edad, digamos; estas confusiones que está viviendo no tienen nada fuera de lo común ni nada malo. Solamente le comenté que estas cosas ella tenía que vivirlas y guardárselas, a menos que quisiera contárselo a alguien de mucha confianza, porque le expliqué que la sociedad actual y las personas actualmente no tienen una visión muy positiva de esto, sobre todo si es en niños. (profesor, Valparaíso, dos años de experiencia)

En este punto cabe hacer una reflexión respecto a las distinciones normativas que realizan los proyectos religiosos. Los entrevistados adscritos a colegios religiosos (en el caso de este estudio: católicos, bautistas y adventistas) señalan que sus proyectos educativos defienden con mayor transparencia una concepción tradicional de la sexualidad y la familia, aunque ello no implica de suyo que existe una discriminación hacia los estudiantes LGBTI+. Notable en este sentido es el testimonio de un practicante en un colegio católico privado de élite, donde a pesar de su adscripción religiosa se observa una connivencia entre estudiantes y docentes para respetar las manifestaciones homoeróticas y las identidades que tensionan la norma, algo aparentemente contradictorio con la naturaleza del proyecto institucional. A su juicio, la clave está en la relevancia del proyecto educativo que enfatiza una comprensión de los valores religiosos centrados en la convivencia y la autonomía personal antes que en la observancia de preceptos o dogmas. Por el contrario, en el caso de los 
establecimientos adventistas, se evidencia con mayor frecuencia la presencia de discursos abiertamente homo/lesbo/bi/transfóbicos, que constituyen formas de violencia abierta y problemática a ojos de los docentes, y donde la naturaleza prescriptiva que tienen las normas religiosas en tales colegios impide tanto la discusión sobre el tema como la visibilidad de las orientaciones sexuales, identidades y expresiones de género diversas, incluso, a pesar de la existencia de normas y orientaciones que a este respecto ha elaborado la política educativa.

Este tipo de relatos revelan la importancia de la cuestión de la visibilidad. A lo largo del estudio se constata que puede haber diferencias importantes y orientaciones que son divergentes en relación con la valoración del comportamiento y las recomendaciones que se entregan al estudiantado sobre cómo conducirse (como lo muestra la cita donde el profesor actúa por cuenta propia ante la poca confianza que siente en los demás profesionales). Esta tensión está presente a lo largo de varias entrevistas, destacándose aquellos docentes que, a pesar de señalar no tener inconvenientes con que la persona se "declare" como homosexual, manifiestan objeciones personales respecto al afecto visible entre estudiantes cisgénero no heterosexuales; o la referencia a otros profesores en la escuela que aceptan a los alumnos gays mientras no sean "locas", o a las lesbianas mientras no sean "camionas". La expresión de género reaparece como cuestión a vigilar.

Por último, cabe señalar que este régimen de visibilidad no es igual para todos los sujetos: la diversidad sigue siendo prácticamente invisible en el caso de alumnos bisexuales, se vuelve visible cuando estudiantes homosexuales (gays o lesbianas) deciden salir del clóset, y se convierte en altamente visible cuando ocurre algún proceso de transición de género de un o una estudiante (Rojas et al., 2019). En parte, esto se sostiene en la retórica del "en la escuela todos son iguales y no necesitan distinguirse por su sexualidad" que movilizan algunos docentes, lo que impide profundizar en las estructuras que producen la diferencia y explican esta desigualdad de lo visible.

Adicionalmente, y considerando además la insistencia en la mayor naturalidad de los jóvenes respecto a la diversidad sexual y de género, llama la atención que no se formule ninguna crítica directa a la persistente violencia simbólica todavía presente dentro de este grupo, que también aparece en el relato. Los mismos docentes relatan incidentes donde han debido intervenir para evitar la discriminación hacia estudiantes LGBTI+. Desde este punto de vista, los cambios sociales no necesariamente se reproducen de modo lineal dentro de la escuela. Por el contrario, se debe entender que cada establecimiento es también una organización que produce normas sobre la diversidad que necesitan ser analizadas en su contexto.

\section{La Precariedad de la Formación Especializada y la Importancia del Conocimiento Informal}

Sistemáticamente, los entrevistados señalaron que la formación en temáticas de diversidad sexual y de género es inexistente dentro de su currículo de formación inicial docente. Cuando esto se aborda es solo tangencial y mínimamente: siempre es un contenido de psicología evolutiva, pero presentado de modo superficial. Cuando se habla de diversidad, el foco de la formación universitaria estaría puesto más que nada en estilos de aprendizaje y las necesidades educativas especiales, sin que exista atención a otras nociones usualmente movilizadas en la escuela sobre todo en lo que refiere a convivencia escolar (estudiantes migrantes, diversidad sexual, situación de discapacidad). Es durante el ejercicio profesional que se reciben algunos aprendizajes formales en la materia, la mayor parte de las veces, mediante instancias de capacitación excepcionales (no orgánicas) que pueden variar en profundidad y enfoque.

Nula, nada, no existe. Bueno, en ninguna parte. Yo estuve en un Congreso sobre el tema trans en Santiago, y ni a los médicos, ni a los médicos los forman para atender pacientes trans, para atender lesbianas. A los profesores tampoco, no es parte de la malla; a nosotros no nos enseñan a tratar con estudiantes, no nos enseñan qué es lo que tenemos que hacer cuando un estudiante nos dice "profe, sabe qué, le conté a mi 
papá que soy gay y me va a echar de la casa”, no sabemos cómo enfrentarlo. Puede haber afectado el hecho de haber estudiado en una universidad católica; pero tengo entendido de que en ninguna universidad, por lo menos en pedagogía, es parte de la malla (...) Al menos yo, tuve cero formación y me tuve que educar sola. (profesora en práctica, Valparaíso)

En contraste con lo anterior, los aprendizajes sobre diversidad sexual y de género vienen de la mano de instancias informales tales como medios de comunicación, búsquedas en Internet y, en el caso de los profesores más jóvenes, debates y seminarios organizados por colectivos estudiantiles en sus respectivas universidades. Es particularmente importante la asociación que los practicantes realizan con las movilizaciones feministas de 2018 donde las cuestiones de diversidad sexual aparecen también como un capítulo dentro del debate que se instala en sus casas de estudio. Los docentes de más antigüedad tienden a referir dificultades de acceso a la información, atribuyéndola a su adscripción a instituciones educacionales comparativamente más conservadoras. Como consecuencia de lo anterior, existen dificultades para explicar el significado de la sigla LGBTI+. La gran mayoría de los entrevistados asocia adecuadamente las tres primeras letras con tres identidades: lesbianas, gays y bisexuales, existiendo algunas diferencias con relación a la T (transexuales, transgénero, travestis) y prácticamente total desconocimiento del significado de la letra I (solo una entrevistada explicó correctamente la semántica de la palabra intersexual). Se aprecia también un caso donde no hay adecuada claridad en la diferencia entre orientación sexual e identidad de género. En dos casos se hace referencia a la posibilidad de incluir la letra Q (queer) dentro del acrónimo. Cualquiera sea el caso, la sigla es entendida como descriptor de una diferencia identitaria.

Es importante contrastar estos hallazgos con el análisis de mallas curriculares realizado. Sobre un total de 132 programas analizados, 60 no presentan ningún curso relacionado con psicología, aprendizaje o desarrollo. En contraste, 19 programas presentan dos cursos en la materia, en cuyo caso se separan contenidos vinculados a psicología del desarrollo y psicología del aprendizaje (o cognitiva, como también se le denomina en algunas carreras). Para los restantes programas que presentan un solo curso bajo esta denominación, la marca predominante corresponde a Psicología Educacional, nuevamente bajo diferentes nombres de curso: Psicología del aprendizaje, Desarrollo psicológico del estudiante en contexto educativo, Psicología y aprendizaje. En este caso resultan minoritarios los contenidos vinculados a psicología del desarrollo (11 casos adicionales). Este hallazgo es coincidente con lo expresado en las entrevistas donde la cuestión de la diversidad se relaciona más bien con los estilos de aprendizaje y en alguna medida con las necesidades educativas especiales y no con otros contenidos de diversidad que deben gestionar en su trabajo como docentes. En el caso particular del desarrollo afectivo y sexual este podría, eventualmente, estar contenido en los cursos de psicología del desarrollo, pero como se puede deducir en el análisis de mallas, este contenido tiene menor desarrollo relativo frente a otros componentes de la psicología (de 132 mallas, solo 30 incluyen la enseñanza del ciclo vital de la niñez y la adolescencia).

Este panorama contrasta fuertemente con la formación en género y sexualidad. Del total de mallas curriculares analizadas, solamente una tiene incluido un curso relativo a esta materia: "Sexualidad y convivencia humana", correspondiente a una pedagogía en filosofía de una universidad laica de la región de Valparaíso. Esto es relativamente esperable considerando que desde el año 2011 el currículo nacional de enseñanza media estableció que los contenidos de sexualidad humana serían abordados por esta disciplina. Ahora bien, cuando se amplía el foco a cursos donde se aborden las cuestiones de diversidad, el panorama se modifica un poco: 39 carreras tienen algún curso donde se aborda explícitamente la cuestión de la diversidad en la escuela, bajo las siguientes denominaciones: Taller de inclusión escolar (4 casos), Diversidad y educación (4 casos) Diversidad e 
inclusión (3 casos), Derechos humanos y diversidad (3 casos), Diversidad e interculturalidad (3 casos), Diseños inclusivos de aprendizaje (2 casos). El resto de los casos corresponden a cursos con nombres que no se repiten en otras instancias. De la información disponible en los sitios web no puede inferirse el grado de profundidad que la cuestión del género y la sexualidad puedan tener en este tipo de formación.

\section{Tabla 2}

Sintesis de Análisis de 132 Mallas Curriculares

\begin{tabular}{|l|l|l|l|l|}
\hline \multicolumn{5}{|l|}{ Número de carreras que cuentan con un curso en las siguientes áreas } \\
\hline $\begin{array}{l}\text { Psicología del } \\
\begin{array}{l}\text { Desarrollo y del } \\
\text { Aprendizaje }\end{array}\end{array}$ & $\begin{array}{l}\text { Psicología del } \\
\text { Desarrollo }\end{array}$ & $\begin{array}{l}\text { Psicología del } \\
\text { Aprendizaje }\end{array}$ & $\begin{array}{l}\text { Género y } \\
\text { sexualidad }\end{array}$ & \multicolumn{2}{l|}{ Diversidad } \\
\hline 19 & 11 & 42 & 1 & 39 \\
\hline
\end{tabular}

Fuente: elaboración propia

Esta falta de conocimiento tampoco es remediada en el ejercicio profesional pues las eventuales capacitaciones en la materia son escasas y aparecen más bien vinculadas a preparar a los docentes para desarrollar un programa de educación sexual. Ahora bien, la educación sexual que imparten hoy las escuelas aborda escasamente la cuestión de la diversidad de orientaciones sexuales, identidad y expresión de género. Esto no debería resultar sorprendente, atendiendo a la amplia heterogeneidad de iniciativas privadas que se hacen cargo de la educación sexual en el país, donde los énfasis suelen estar puestos en cuestiones de salud sexual y reproductiva y en la disputa sobre los valores morales que deberían guiar las decisiones personales en materia de comportamiento sexual (Figueroa, 2012; Palma et al., 2013) En consecuencia, los profesores deben hacerse cargo de unidades de orientación que abordan limitadamente estas materias, muchas veces en un mero rol de ejecutores, sin participación en su elaboración. Independientemente de si el proyecto escolar es progresista o conservador, la educación sexual sigue enfatizando el tratamiento de la diferencia asociándolo más bien a la afectividad y sexualidad personal, sin que se trabaje reflexivamente el modo como las distintas orientaciones sexuales, identidades o expresiones de género cuestionan la norma dominante. Si bien algunos entrevistados señalan que en sus colegios existe un paraguas general de trabajo que favorece la tolerancia y el respeto, los mismos no bastan para atender y gestionar las cuestiones relacionadas con la diversidad sexual y de género en su multiplicidad de facetas.

La profesora de Biología abordará el tema (de la reproducción) porque viene en el programa de estudio, pero no sé si aborda la diversidad sexual. No sé. Porque nosotras, institucionalmente no hemos tratado el tema. Yo llevo once años acá en el Colegio, y que hayamos discutido sobre diversidad sexual, nunca. Lo único que nos señala Dirección es que "en algún minuto van a haber alumnos transexuales, y bueno tenemos que estar preparados, tenemos que aceptarlos porque hay una ley y somos cristianos y hay un panel valórico" como que: si llega a pasar, hay que aceptarlo, asumirlo y bien. Pero, como te digo, no hay un debate acá. (profesora, Valparaíso, más de seis años de experiencia)

Ahora bien, cuando se diferencian las entrevistas en relación con la disciplina estudiada/enseñada por el profesor, se aprecian diferencias importantes. Aquellos docentes que se asocian a disciplinas de corte humanista -a diferencia de carreras ligadas a las matemáticas y las ciencias duras- suelen presentarse a sí mismos, comparativamente, como más cuestionadores de la norma social sobre el 
género y la sexualidad. En este sentido reconocen que dentro de su formación inicial docente tenían más probabilidades -0 interés- de acceder a instancias informales de aprendizaje sobre diversidad sexual y de género. Al mismo tiempo, señalan tener más espacios didácticos donde abordar estas materias. Este hallazgo contrasta en parte con una de las conclusiones del estudio de María Teresa Rojas et al. (2019) donde se afirma que la variable de distinción corresponde a si la asignatura en cuestión es medida o no por pruebas estandarizadas: aquellas menos vigiladas como Arte o Inglés, por ejemplo, tendrían más espacio para discutir estos contenidos que otras, por las libertades que otorga no tener que cumplir con la presión de resultados. En el caso de este estudio las asignaturas de Lenguaje e Historia -siempre por iniciativas personales, nunca institucionales- son identificadas también como espacios donde se pueden tratar los contenidos de género y sexualidad mediante el plan de lectura o el de formación ciudadana.

Yo creo que en las Facultades de Humanidades en general estos temas sí se abordan.

Yo estudié en la Escuela de Ingeniería y después estuve en la Escuela de Educación; entonces, yo sí creo que en las otras disciplinas esto es distinto y creo que los estudiantes de esas carreras sí pueden haber tenido experiencias diferentes a la mía. (profesor en práctica, Santiago)

A mí me parece que el trabajo entre la disciplina [filosofía] y la pedagogía debe mostrarse en temáticas concretas. Creo que el problema de género es una temática concreta que el profesor tiene que abordar y debe ser abordado entre la disciplina y la pedagogía (profesor, Santiago, menos de dos años de experiencia)

Distinta es la situación cuando se trata de ejercer como profesor jefe, pues en este caso el abordaje de la diversidad por orientación sexual, identidad y expresión de género responde al tratamiento de la contingencia (acompañamiento de procesos personales) o a cumplir lo estipulado en los programas de orientación (que incluyen los planes de educación sexual). Allí, la adscripción disciplinaria del docente es irrelevante, salvo en lo relativo a la formación "informal" que pudieron recibir en su formación inicial docente aquellos profesores más jóvenes. Pasan a ser más relevantes, más bien, las habilidades personales, así como las experiencias previas vividas en relación con esta materia.

\section{El Efecto de una Cultura Organizacional Centrada en la Gestión}

En las escuelas, el reconocimiento de la diversidad de orientaciones sexuales, identidad y expresión de género opera en un nivel casuístico. Cuando los entrevistados refieren a alguna experiencia de este tipo siempre hacen alusión a situaciones de individuos particulares que pueden ser delimitadas con claridad una vez que se vuelven visibles. Cuando esto ocurre, el "caso" se entiende en dos niveles paralelos: uno relacionado con el acompañamiento más psico-social de los individuos, y otro vinculado a la gestión de la convivencia (lo que incluye, la mayor parte de las veces, prever y manejar la reacción de los apoderados). En ambos casos, lo importante es mostrar la propia capacidad de gestionar "un problema"; y de allí la crítica a la formación inicial docente recibida, pues aquella no entrega ningún elemento de juicio para enfrentar tal situación. En numerosas entrevistas se demanda formación y capacitación especializada para así “adquirir herramientas" pues de otro modo se termina actuando sin la debida complejidad. Como profesor, te podrías enfrentar tú a una situación concreta, de aula, con colegas, con apoderados (o) con tus estudiantes, (y tienes que pensar) cómo abordarlo, y no sé si hay un manual. Por ejemplo, en la sala, donde hay de todo, y no solo es la diferencia de género la que tienes que trabajar, sino todas las diferencias. Y como nadie está preparado para trabajar todas las diferencias 
terminamos haciendo la clase estándar (profesor, Santiago, más de seis años de experiencia)

Sostenemos que el uso de tal vocablo no es arbitrario. La noción de herramienta refiere aquí a dispositivos prácticos que permitan actuar en concreto y modificar una situación particular, pues los cambios culturales no bastan para estabilizar una solución. En este sentido, tampoco es indiferente el hecho que las cuestiones vinculadas al género y la sexualidad sean presentadas como un asunto individual. Acompañar estudiantes, aplicar el manual de convivencia, contener reacciones desmedidas o inadecuadas de los apoderados son presentadas como situaciones que hay que resolver más bien una a una, sin que la casuística logre cuestionar el orden social en el cual se fundamentan las diferencias entre individuos o el orden jerárquico entre identidades sexuales y de género. Esto se sostiene, además, en la permanente referencia a situaciones que han debido ser resueltas sin que eso implique necesariamente una actitud participativa del estudiante atendido. En este sentido, se entiende que los individuos que tensionan la norma esperada deben de algún modo ser representados en su diferencia, sin que exista necesariamente una problematización de la norma o una reflexión de por qué el tema se debe incluir en la didáctica más allá de una mera "integración de lo que quedaba fuera".

El colegio respeta bastante lo que es la diversidad sexual y la identidad de género. Nosotros incluso sabemos qué alumnos son diversos, por decirlo así, y son muy respetados. Incluso se sabe cuáles son las parejas, y cuando hay alguna duda o sospecha de alguien, se llama, se conversa, y así han salido alumnos que han estado en la duda, se le ha llevado a psicólogo o a tratamientos para, digamos, poder orientarlos, en esa parte. (profesor, Valparaíso, más de seis años de experiencia)

La directora nos decía, "chiquillas ustedes diseñen sus clases, diseñen sus ppt y creen su propio material donde haya familias monoparentales, familias homosexuales, y que también se muestre una pareja. Si van a hablar -no sé- del día de San Valentín, muestren una pareja homosexual, porque ustedes no saben si alguno de sus estudiantes puede pertenecer a la comunidad y va a ser importante para ese estudiante verse representado o, al menos, ver representada a su comunidad en la sala de clases". Ella lo decía como para darnos confianza y también como para motivar e interesar más a nuestros estudiantes. (profesora en práctica, Valparaíso)

Esto es algo que se agudiza en el caso del tratamiento de los estudiantes trans. A lo largo del estudio los entrevistados dan cuenta de las discusiones que, dentro de la escuela, intentan regular el uso de los baños, del uniforme, la reacción de los apoderados y decidir si se autoriza o no el uso del nombre social. Llama la atención en este caso el desconocimiento u omisión respecto a los puntos establecidos en las circulares y orientaciones de la Superintendencia de Educación y el Ministerio de Educación que regulan esta cuestión (Circular $\mathrm{N}^{\circ} 0768$ de la Superintendencia de Educación "Derechos de niños, niñas y estudiantes trans en el ámbito de la educación" y las "Orientaciones para la Inclusión de las personas lesbianas, gays, bisexuales, trans e intersex en el Sistema Educativo", respectivamente), lo que redunda en que las narrativas apunten más bien a la gestión organizacional antes que al cumplimiento de las normas de inclusión que estos documentos expresan.

Ahora bien, esta clase de gestiones nunca son independientes de cómo se entiende la autoridad dentro de la escuela. A lo largo de las entrevistas, el lugar de trabajo tiende a ser representado como un espacio donde las jerarquías se establecen a partir del ejercicio de una autoridad vertical, algo esperable en virtud de la asimetría propia de la relación pedagógica (Rollin, 
2012). Esta verticalidad queda clara en aquellos ejemplos donde los profesores practicantes relatan cómo se imponen frente a los estudiantes y frenan cualquier comportamiento discriminatorio, pero se abstienen de actuar si la discriminación es ejercida por un docente en ejercicio, especialmente si dicho docente es su profesor guía. Ahora bien, este ejercicio de la autoridad se complejiza cuando las normas sociales cambian y ya no son tan claros los parámetros en los cuales se sostiene esta desigualdad. Por tal razón, los docentes relatan que, a medida que avanzan en su trayectoria profesional, la firmeza y la consistencia personal son cruciales a la hora de asegurar respeto frente a los estudiantes y sus pares, pudiendo de este modo movilizar algunas acciones que modifiquen el actuar institucional y cuestionar la reproducción de ciertas normas de género y expresión de la sexualidad.

Lo anterior no significa en caso alguno actuar de modo autoritario frente a otros o revolucionario en relación con las prácticas escolares existentes, sino simplemente mostrarse contenedor y capaz de mantener límites claros de convivencia. No obstante, tal como lo señala Sylvie Ayral (2011) muchas veces esto implica adoptar comportamientos tradicionalmente asociados al rol masculino: sancionar y recordar la verticalidad de las relaciones. La autoridad por lo tanto no está asociada al cargo sino a como se gestionan las interacciones dentro de la escuela. Ahora bien, los cambios en la norma social en relación con el género y la diversidad sexual suponen para los docentes nuevas situaciones en las que se espera que expresen su coherencia personal, lo cual tensiona su posición dentro de la comunidad educativa. Como lo revelan algunas citas, en ocasiones lo que prevalece es la persona y no el docente.

Es súper valioso cuando uno es más joven y está empezando a hacer clases, mostrar todas sus limitaciones ante los estudiantes. Eso, más que colocarse una careta, armarse el personaje del profe que lleva años. A veces es mucho más fácil ser súper honesto, y decir "soy homofóbico", y los alumnos te lo agradecen mucho más (...) No tengo idea como se hace con los más chicos, no te voy a mentir. Pero los adolescentes, de enseñanza media por lo menos, te agradecen mucho más que tú seas muy honesto con ellos con respecto a estos temas. Además, ellos son muy morbosos y curiosos respecto a quién eres tú, qué eres tú, qué haces tú, cómo vives tú tu sexualidad, o tu identidad, no solo tu sexualidad, sino cómo vives tú, quién eres tú. (profesor, Santiago, más de seis años de experiencia)

Profesora: En este colegio necesitan muchísimo ser escuchados. A lo mejor yo no les voy a dar una solución para la vida, pero sí mucha escucha, (hacerlos sentir) apoyados en su condición, no sexual, sino apoyados en su condición de persona. Eso. Y te digo que los estudiantes me tienen harta buena, los que son raros, como dicen por ahí. ¿te fijas? Incluso les gusta como soy, como me visto, como hablo, como me pinto las uñas. Nos llevamos bien. / Entrevistador: ¿Así que te has dado cuenta de eso? / Profesora: Es que me lo dicen. A veces me ha tocado entrar a salas, ponte tú sexto básico, y me dicen "ah viene la miss que es tan regia, tan estupenda", "a ti te voy a hacer caso porque me gustas", y estamos en matemática, que es una cuestión como difícil. (profesora, Santiago, más de seis años de experiencia)

Llama especialmente la atención en la última cita como la profesora descansa en su coherencia de género (la expresión de feminidad) y señala que este recurso le permite gozar de la confianza de los "raros". Esto contrasta con la cita anterior donde el profesor habla de la necesidad de ser sincero como mecanismo para asegurar la confianza del alumnado y asegurar su autoridad sobre ellos. De allí que se deduce que la coherencia depende de una relación compleja de factores. Quizás donde se hace más evidente esto es en la contradicción que enfrentarían aquellos docentes que se presentaron 
a sí mismos como no heterosexuales (lesbiana y gay). Para ellos las posibilidades de agencia personal son más complejas: por una parte, deberían estar dispuestos a ser relativamente honestos respecto a su orientación sexual si los estudiantes lo preguntan, pero al mismo tiempo señalan que deben ser cautelosos de la reacción de otros adultos, a sabiendas que ser gay o lesbiana puede perjudicarlos en su trabajo. Esto es consistente con los hallazgos de Connell (2015) donde ser adulto homosexual en la escuela es problemático no por la orientación sexual en sí, sino porque el ejercicio docente está cada vez más desexualizado en el contexto escolar.

A lo anterior, habría que añadir la ambivalencia de la sociedad chilena donde la aceptación de la homosexualidad no es necesariamente "estable", pues aunque se acepta crecientemente la reivindicación de derechos políticos LGBTI+ se mantiene un rechazo a que individuos no heterosexuales trabajen con menores de edad (Barrientos, 2015). Como lo muestran las múltiples referencias que los entrevistados hacen sobre la presencia de otros profesores gays y lesbianas en la escuela, lo que prevalece es la sospecha permanente sobre su sexualidad y la afirmación de que no podrían salir del clóset libremente. No obstante, es importante mencionar que en los dos casos donde entrevistados se presentan a sí mismos como sujetos no heterosexuales, la propia identidad no se ha hecho visible en las escuelas donde trabajan, por lo que su sexualidad no interviene en la descripción de diferentes situaciones donde son interrogados respecto de su postura frente a la diversidad sexual o de género. De hecho, en uno de los casos una profesora lesbiana decide portar una piocha con la bandera gay en la solapa de su delantal la cual es presentada ante los estudiantes como el signo de ser una "aliada" y no de ser una mujer lesbiana. La gestión de la temática, nuevamente, es el resultado de una estrategia individual.

Por último, nos parece relevante mencionar el hallazgo encontrado en dos entrevistas en particular. Este alude a la posición que tienen las temáticas de diversidad sexual y de género en contextos de alta vulnerabilidad social. En tales casos, se narra que existen cuestiones "más problemáticas" que concitan mayor atención por parte de la comunidad educativa: drogas y violencia. En estas escuelas la cuestión del género y sexualidad -al ser considerado un problema personal- tiende a ser presentada como "menos urgente", porque el impacto en la convivencia escolar es menor en comparación con otras situaciones. Si bien este elemento resulta minoritario dentro del contexto del estudio -y no podemos establecer un criterio de representatividad al respecto-, la alusión a esta jerarquía de "problemas" ilustra adecuadamente la relación entre la cultura institucional y ciertas condiciones materiales de funcionamiento institucional que influyen en la gestión de la temática.

\section{Discusión}

En el título de este artículo hemos utilizado la expresión "aceptación silenciosa" con el fin de ilustrar la predisposición de los docentes que, reconociendo la validez de la diversidad de orientaciones sexuales, identidades y expresiones de género mantienen, sin embargo, una cierta cautela a la hora de expresar sus opiniones o tratar de modificar sus prácticas pedagógicas en favor de la inclusión. En otras palabras, la aceptación silenciosa supone que se cree que la diversidad no es mala, que se valida la diferencia, pero sin sentirse totalmente seguro de expresar esta opinión ni de lo deseable que sea visibilizar esa diferencia. Desde este punto de vista, tal aceptación no es una disposición activa, visible y sistemática para modificar las acciones que tienen lugar en la escuela, sino más bien sería una actitud adaptativa, individualizante y en cierto modo, pasiva. En principio, esta disposición no estaría relacionada con el género y región donde se desempeñan los docentes, sino más bien, con el modo como la trayectoria personal sintetiza la lectura de los cambios sociales 
que han ocurrido en el país, y la potestad que cada sujeto se autoatribuye para contradecir o no las normas que imperan en las escuelas donde trabajan.

La mayor aceptación de la diversidad que se estaría instalando en Chile no significa a priori que los adultos cambiarán conforme con ello, sino que se requiere de otros procesos reflexivos personales. Estos procesos están vinculados al desarrollo de sentimientos de empatía con otros sujetos, pero también a la toma de conciencia del propio rol y de cómo las actitudes hacia la diversidad están asociadas a transformaciones sociales más amplias que los casos que se intenta intervenir. Esto, porque independientemente de que en los establecimientos los manuales de convivencia o los planes educativos institucionales insistan en cuestiones como el respeto y la no discriminación, en la práctica la falta de referencias específicas a la diversidad sexual y de género dentro de estos cuerpos normativos, tiende a invisibilizar los tipos de violencia específica que subsisten en contra de este colectivo (Barrientos y Echagüe, 2018; Kosciw y Zongrone, 2019). Esta condición, presente a lo largo de todo el sistema escolar, solo tiende a romperse cuando se vuelven reflexivas las estructuras de producción y reproducción de la diferencia (Miller, 2016).

En el caso de las escuelas, la distinción entre identidad pública y sexualidad privada mantiene en la invisibilidad relativa a los individuos que tienen una identidad homosexual (Le Mat, 2014) lo cual permite establecer todavía asociaciones gruesas entre comportamientos no convencionales del género y la sospecha sobre la sexualidad del individuo (Wittig, 1980). En paralelo, impide ver que todos los individuos están conminados socialmente a mostrarse como sujetos sexuados (Bozon, 2009) lo que deriva en distintas estrategias para buscar reconocimiento que, en el caso de la diversidad por orientación sexual, identidad y expresión de género, es entendida como una "sobreexposición", tal como lo constatan algunos de los entrevistados. En términos generales, podemos afirmar que para los docentes desafiar la norma es visto más bien como un asunto cultural (gestionar la conducta según los códigos permitidos dentro de un grupo social) que como una cuestión política (voluntad explícita de un sujeto de transformar su realidad personal). En otras palabras, la invisibilidad de la diversidad redunda en que los sujetos que no siguen el patrón tradicional de género o sexualidad sean presentados más bien como individuos pasivos, es decir, como alguien que se ha adaptado a las circunstancias, sin ser necesariamente agente de su propia identidad.

Ahora bien, en términos institucionales, la visibilidad no está limitada solo a la casuística. Por una parte, lo que las entrevistas omiten son las condiciones materiales o culturales específicas de una organización, que permiten la emergencia de un determinado caso. A lo largo del estudio, se puede constatar como la situación de visibilidad varía de un establecimiento a otro. Si seguimos los planteamientos realizados por Rojas et al. (2019), tanto el capital cultural de las familias como la impronta de la dirección del establecimiento podrían fungir como factores diferenciadores en esta materia. De este modo, la visibilidad o "aparición" de los casos es el resultado de un modo general de comprender la diversidad. Es fácil constatar como los docentes refieren al tema a partir de dos cuestiones fundamentales: los alumnos cisgénero no heterosexuales y los procesos de transición de género de algún estudiante. Luego, la diversidad en relación con la expresión de género aparece como un asunto relativamente marginal, porque no recibe mayor atención en comparación con los temas precedentes o porque no forma parte de la reflexividad de los sujetos adultos en la escuela; aunque sí aparece implícitamente, por ejemplo, cuando se habla de que hay "sospechas" de que un estudiante es homosexual (si bien el estudio no ahondó específicamente en cuál es el sustento de estas "sospechas"). Este ordenamiento, junto con la falta de reflexión sobre las condiciones organizacionales que permiten emerger los casos, impide que los docentes puedan ir más allá de las sentencias generales que ha sido referidas en este estudio, es decir, de la idea que en Chile se puede ser lesbiana, gay o bisexual, pero hay que estar consciente de los costos y eventuales problemas que un individuo enfrentará, todo lo cual llama a la discreción. 
La situación anterior difícilmente puede ser enunciada y transformada si no existen formas de instrucción que puedan modificar estas creencias y las prácticas que de aquellas se derivan. Al examinar tanto la formación inicial docente como la educación sexual que se imparte en los colegios, se constata un posicionamiento desde la precariedad. Utilizamos este término para ofrecer un concepto que permita englobar la sensación descrita por los docentes: ante la ausencia de una adecuada formación, desarrollan una crítica hacia sus propias universidades y describen además una sensación de inseguridad cuando deben enfrentar situaciones concretas que han de gestionar y donde el conocimiento formal aseguraría un mejor desempeño. Al mismo tiempo, esta precariedad se mantiene en la medida que el abordaje casuístico de la diversidad por orientación sexual, identidad y expresión de género no logra romper con las nociones de normalidad que se transmiten consuetudinariamente en la escuela y que son reforzadas también por la escasa formación universitaria que hay en materia de inclusión. Tendríamos que sumar a lo anterior el hecho que, en los espacios universitarios, dicha formación va neutralizando la diferencia precisamente a través de un etiquetaje estático de las identidades que conviven en la escuela (Ahmed, 2012; Ferguson, 2012; Matus e Infante, 2011). Esto es algo que no observamos en este estudio, pero que podemos intuir ante la falta de asignaturas que problematicen la noción de inclusión y la ausencia de discursos que refieran a ello en las entrevistas; también, se desprende de la dificultad de visualizar la expresión de género como objeto de preocupación en materias de inclusión, al no corresponder con una "identidad" o etiqueta definida.

En este sentido, las posibilidades de formular críticas al orden prevalente son limitadas. Esto es todavía más acusado cuando se analiza el acoplamiento entre actitudes docentes y cultura organizacional. Diferentes posiciones producen diferentes experiencias y, por lo tanto, distintas predisposiciones a enfrentar estas temáticas y eventualmente mostrar una postura crítica frente al orden de género y sexualidad. Ser profesor practicante o profesor experimentado no es algo neutro. Esto no tiene que ver con la falta de reconocimiento de la cultura organizacional (de hecho, muchos entrevistados jóvenes describen con claridad los valores y normas sociales de sus escuelas) sino más bien con la manera como se puede ejercer la autoridad y delimitar las formas de acompañamiento estudiantil. Las posibilidades de jugar entre persona y "personaje", la capacidad de asumir un rol de agente y de mediar entre distintos universos normativos, dependen de una trayectoria en específico y de la forma como se va reconociendo la validación profesional. En el caso de este estudio, el género del docente no parece ser relevante, aunque sí su sexualidad, como lo evidencian los casos de profesores no heterosexuales para quienes las reglas de aceptación solo estarían referidas a los estudiantes y no a los docentes. Esto muestra cómo las reglas sociales se modifican en función de los roles que cada sujeto ocupa dentro de la comunidad escolar.

La validación personal de la diversidad no produce cambios si no es mediante una ruptura de las representaciones dominantes. La escuela no solo es un lugar de transmisión del conocimiento, sino también un espacio generador de experiencias socializadoras, donde los docentes son intermediadores entre un orden normativo social y los criterios autónomos de sujetos concretos (Dubet y Martuccelli, 1996). Como ambos sistemas de valores no necesariamente son coherentes entre sí, lo que tiende a operar es una idea de gestión del conflicto. Esto queda claro en el hecho que casi la totalidad de los entrevistados se muestra abierto y aceptador de la diversidad sexual y de género, pero al mismo tiempo se muestran desconcertados respecto a cómo enfrentar situaciones donde el comportamiento de otros contradice ese valor, especialmente si esto viene de parte de sus pares. En ese escenario predomina un cálculo de acción, donde el "disponer de herramientas" respaldaría mejor el propio actuar, eventualmente validándolo desde un saber experto. Ante la sensación de precariedad de la formación las propias herramientas se evalúan como insuficientes, lo que implica personalizar las decisiones (ser persona antes que profesor); esto, a su vez, supone un riesgo de sobreexposición dentro de un espacio educativo que ha tendido a despersonalizar y 
desexualizar la labor docente (Connell, 2015). Todo esto genera una incomodidad que refuerza la calidad "silenciosa" de la aceptación a la que se ha hecho alusión: los profesores tratan de pasar desapercibidos en lo que consideran un terreno resbaladizo.

A fin de cuentas, la aceptación silenciosa dice relación con las consecuencias que, dentro de una institución jerárquica como es la escuela, ha tenido el cambio cultural y normativo hacia la diversidad por orientación sexual, identidad y expresión de género. La mutación de los valores en relación con el género y la sexualidad exige un nuevo relato para los docentes que deben adaptarse al "esto ya no es como antes". En este sentido, los profesores enfrentan prescripciones sobre cómo ser coherente y sobre cómo actuar que no necesariamente están de acuerdo con sus propios valores y experiencias. Luego, la autoridad para hablar, para intervenir, dependería también de otros elementos personales: del saber gestionar, del saber mostrar habilidades "blandas", de herramientas técnicas específicas, todas cuestiones que van más allá de las disciplinas y el conocimiento que deben movilizar habitualmente en la escuela. En este sentido, no deja de ser llamativo que los docentes insistan en sus propias competencias (o incompetencias) para enfrentar los problemas, en lugar de recurrir a dispositivos normativos legales que regulan el quehacer escolar y que sancionan la discriminación a nivel nacional (como podrían ser la Ley Antidiscriminación y más recientemente la Ley de Inclusión Escolar).

Ciertamente, en este estudio no hemos profundizado en cómo la formación inicial docente entrega competencias específicas, pero sí podemos asumir que el docente sigue entendiéndose a sí mismo como un formador que tiene que ofrecer algo adicional a lo que la cultura fuera de la escuela enseña (Fernández, 2018). Que los alumnos sean más aceptadores con la diversidad no basta para que un profesor cambie su propio actuar. Eso adicional, eso que va más allá de la mera opinión o de la gestión de un caso, es algo que todavía necesita ser reflexionado. De otro modo, no puede construirse una vOz autorizada que promueva que la aceptación -como acuerdo y valoración de la diversidad sexual y de género- salga del espacio individual, silencioso, de cada profesor, para empezar a ser un contenido y práctica que circule visible e institucionalmente en las escuelas, a nivel de estrategias pedagógicas, de contenidos curriculares, de didáctica, de proyecto educativo institucional, de reglamentos de convivencia por nombrar sólo algunas dimensiones.

\section{Conclusiones}

A partir de lo ya señalado podemos ofrecer una reflexión adicional. Tal como lo plantea François de Singly (2010), en las sociedades occidentales las lógicas de reconocimiento están en un punto de tensión: se debe asegurar un tratamiento igualitario de los individuos respetando al mismo tiempo la reivindicación de sus diferencias pues aquellas son estructurantes de su identidad. De acuerdo con el autor, cuando se reduce un sujeto a una sola etiqueta se le restringe el derecho a elegir la categoría desde la cual quiere ser reconocido ante los demás.

Esto es algo que ocurre claramente en relación con la diversidad por orientación sexual, identidad y expresión de género (OSIEG). Cuando los docentes observan a quienes tensionan la norma como un caso a tratar, simplemente pierden de vista la totalidad de la experiencia de todos y cada uno de los actores escolares, pues todos en conjunto producen y reproducen el régimen normativo sobre la sexualidad en una escuela dada. En este caso, tanto la formación inicial docente como las culturas organizacionales tienden a mantener esta situación en una ficticia estabilidad sostenida en la posibilidad de atender individualmente a quien desafía la norma, sin aportar elementos que permitan romper con la casuística. Si la escuela vive en la paradoja de considerar a los sujetos como iguales, pero buscar diferenciarlos para certificar sus logros (Dubet, 2013), resulta interesante preguntarse por las formas en que las cuestiones relacionadas con la diversidad de 
orientaciones sexuales, identidad y expresión de género responde a esa misma inercia, posicionando individuos dentro de una escala de medición de la "normalidad" que está todavía poco cuestionada.

La sociedad chilena ha cambiado y la diversidad sexual y de género ha dejado de ser un tabú en las escuelas. En este escenario, se instala la idea de que los individuos que tensionan la norma ya no merecen el rechazo sino la escucha activa. Es esa transformación la que probablemente posibilita que los profesores se interroguen, incipientemente, sobre otros aspectos de su quehacer profesional, lo que permite a su vez mirar críticamente tanto la formación recibida como las condiciones de desempeño en la escuela. Por esta misma razón, nos parece importante señalar que cualquier estudio futuro sobre actitudes docentes en torno a la diversidad de orientación sexual, identidad y expresión de género, debería profundizar en el efecto que tienen sobre las mismas elementos como las trayectorias docentes, la participación de los profesores en instancias de formación sobre género y sexualidad, el modo como las escuelas tipifican la discriminación y establecen protocolos de acción frente a ella, la forma como se organiza el acompañamiento estudiantil en cada lugar de trabajo, y la reflexividad que cada docente tiene en torno a la construcción social de las experiencias individuales, por nombrar algunos elementos.

Finalmente, nos parece relevante plantear tres limitaciones del presente estudio. En primer lugar, el no haber contado con profesores de educación física, una asignatura considerada particularmente susceptible a la reproducción de valores sexistas y homo/lesbo/bi/transfóbicos no tanto por la voluntad del profesor si no por la naturaleza segregada y segregadora que tiene la formación deportiva (Devis et al., 2005) que moviliza discursos asociados a la corporalidad, ausentes en otras disciplinas. En segundo lugar, el no haber profundizado en la influencia asociada a la ocupación de un cargo directivo por parte del docente. Podemos suponer que ocupar esta posición podría producir un cambio de mirada sobre la cultura organizacional y por consecuencia, modificar la lectura de los espacios de agencia personal y de las consecuencias que tiene cada decisión curricular y personal. Una tercera y última limitación refiere a la superficialidad con la que se abordaron las experiencias personales de acompañamiento estudiantil. Más allá de la empatía expresada por los entrevistados, existen lecturas más finas de los procesos individuales que todavía están pendientes, como puede ser la toma de decisión respecto a compartir o no la situación de un estudiante o la manera como ciertos casos interpelan la propia sexualidad, identidad o expresión de género.

Esta última cuestión, al mismo tiempo, deja abierta una interrogante que es crucial para el desarrollo futuro de la política educativa: ¿cómo se puede pensar la transición desde una postura silenciosa hacia una que sea capaz de enunciar y modificar institucionalmente la injusticia que produce la norma de género y sexualidad? Responderlo es reconocer que la aceptación silenciosa, pese a representar un cambio favorable frente a la violencia transhomofóbica, es todavía la expresión de un límite en cuanto al justo reconocimiento de los sujetos se trata.

\section{Referencias}

Ahmed, S. (2012). On being included. Racism and diversity in institutional life. Duke University Press. Araujo, K. (2009). El ordinario trabajo moral del sujeto. En K. Araujo (Ed.) ¿Se acata pero no se cumple? Estudios sobre las normas en América Latina (pp. 91-118). Lom.

Astudillo, P. (2016). La inestable aceptación de la homosexualidad. El caso de las escuelas católicas de élite en Santiago de Chile. Revista Latinoamericana de Educación Inclusiva, 10(2), 21-37.

Ayral, S. (2011). La fabrique des garcons. Sanctions et genre au collège. PUF.

Barrientos, J. (2015). Violencia homofóbica en América Latina y Chile. El Desconcierto. 
Barrientos, J., \& Echagüe, C. (2018). El baile de las que sobran. Interrogando la violencia homofóbica en un liceo público chileno. Forum: Qualitative Social Research, 19(1), 1-44.

Barrientos, J. Echagüe, C., Matus, C., \& Astudillo, P. (2020). Homophobic violence against LGBTQ+ youth in a Chilean school. En H. Sauntson \& J. I. Jón Kjaran. Schools as queer transformative spaces. Global narratives on sexualities and gender. Routledge.

Bozon, M. (2009). Sociologie de la sexualité. Armand Colin.

Bourdieu, P. (2000). La dominación masculina. Anagrama.

Bragg, S., Renold, E., Ringrose, J., \& Jackson, C. (2018). 'More than boy, girl, male, female': Exploring young people's views on gender diversity within and beyond school contexts. Sex Education, 18(4), 420-434.

Butler, J. (1990). Gender trouble. Feminism and the subversion of identity. Routledge.

Cáceres, C. \& Salazar, X. (eds.) (2013) “Era como ir todos los días al matadero..." El bullying homofóbico en instituciones públicas de Chile, Guatemala y Perú. [Documento de trabajo]. IESSDEH, UPCH, PNUD, UNESCO.

Catalán, M. (2018). Docentes abriendo las puertas del closet: Narrativas de resistencias y apropiaciones a la heteronormatividad en profesores homosexuales/lesbianas en escuelas públicas y privadas de Santiago de Chile. Revista Latinoamericana de Educación Inclusiva, 12(1), 57-78.

Collins, P., \& Bilge, S. (2016). Intersectionality. Polity Press.

Connell, C. (2015). School's out. Gay and lesbian teachers in the classroom. University of California Press.

Connell, R. (2000). Gender. Polity Press.

Connell, R. (2006). Escuelas y justicia social. Morata.

Connell, R. \& Pearse, R. (2018). Género. Desde una perspectiva global. PUV.

Cumming-Potvin, W. M., \& Martino, W. (2018). Countering heteronormativity and cisnormativity in Australian schools: Examining English teachers' reflections on gender and sexual diversity in the classroom. Teaching and Teacher Education, 74, 35-48

Devis, J., Fuentes, J., \& Sparkes, A. (2005). ¿Qué permanece oculto en el currículum oculto? Las identidades de género y de sexualidad en la educación física. Revista Iberoamericana de Educación, 39, 73-90.

Draelants, H., \& Dumay, X. (2011). L’identité des établissements scolaires. PUF.

Dubet, F. (2010). La sociología de la experiencia. Editorial Complutense.

Dubet, F. (2013). Pour quoi moi ? L'expérience des discriminations. Seuil.

Dubet, F., \& Martuccelli, D. (1996). A l'école. Sociologie de l'expérience scolaire. Seuil.

Duru-Bellat, M. (2008). La (re)production des rapports sociaux de sexe : quelle place pour l'institution scolaire? Travail, Genre et Sociétés, 19(1), 131-149.

Ferfolja, T., \& Ullman, J. (2014). Opportunity lost or (re) written out: LGBTI content in Australia's New National Health and Physical Education Curriculum. En M. Somerville \& S. Gannon (Eds.) Contemporary issues of equity in education. Cambridge Scholars.

Ferguson, R. (2012). The reorder of things. The university and its pedagogies of minority difference. University of Minnesota Press.

Fernández, M. B. (2018). Framing teacher education: Conceptions of teaching, teacher education, and justice in Chilean national policies. Education Policy Analysis Archives, 26(34).

Figueroa, E. (2012). Política pública de educación sexual en Chile: Actores y tensión entre el derecho a la información vs. la libertad de elección. Estado, Gobierno, Gestión Pública, 19, 105-131.

Fraser, N. (2008). Escalas de justicia. Herder.

Fraser, N., \& Honneth, A (2006). ¿Redistribución o reconocimiento? Morata.

Giddens, A. (1992). The transformation of intimacy: Love, sexuality and eroticism in modern societies. Polity. 
Instituto Nacional de Derechos Humanos (INDH). (2017). Informe Anual. Situación de los Derechos Humanos en Chile. Capítulo 3: Realidad y desafío: niñas, niños y adolescentes intersex en contextos de salud y educacionales. Disponible en: https://www.indh.cl/bb/wpcontent/uploads/2017/12/01_Informe-Anual-2017.pdf

Kjaran, J. I., \& Lehtonen, J (2017). Windows of opportunities: Nordic perspectives on sexual diversity in education. International Journal of Inclusive Education, 22(10), 1035-1047.

Kosciw, J. G., \& Zongrone, A. D. (2019). A global school climate crisis: Insights on lesbian, gay, bisexual, transgender \& queer students in Latin America Una crisis global en el clima escolar: Perspectivas sobre estudiantes lesbianas, gays, bisexuales, transgénero y queer en América Latina]. GLSEN-Fundación Todo Mejora.

Laqueur, T. (1994.) La construcción del sexo. Cuerpo y género desde los griegos hasta Freud. Cátedra.

Le Mat, A. (2014). L'homosexualité, une « question difficile» Distinction et hiérarchisation des sexualités dans l'éducation sexuelle en milieu scolaire. Genre, Sexualité et Société, 11. https://gss.revues.org/3144

Maturana, C., Kaeuffer, A., Riquelme, C., Silva, M. P., Osorio, M. R., \& Torres, N. (2016). Conocimientos sobre identidad sexual de profesores y profesoras: ¿Barreras o facilitadores de construcción identitaria? Revista Latinoamericana de Educación Inclusiva, 10(2), 53-71.

Matus, C., \& Infante, M. (2011). Undoing diversity: Knowledge and neoliberal discourses in college of education. Discourse: Studies in the Cultural Politics of Education, 32(3), 293-307.

Miller, S. J. (2016). Teaching, affirming and recognizing trans and gender creative youth. Palgrave Macmillan.

Morgade, G. (2008) Educación, sexualidades, géneros. Tradiciones teóricas y experiencias en un campo en construcción. En G. Morgade (Comp.), Cuerpos y sexualidades en la escuela. De la "normalidad" a la disidencia (pp. 19-39). Paidós.

Morgade, G. (2016). Educación sexual integral con perspectiva de género: la lupa de la ESI en el aula. Rosario: Homo Sapiens.

Neary, A. (2017). Lesbian, gay and bisexual teachers' ambivalent relations with parents and students while entering into a civil partnership. Irish Educational Studies 36(1), 57-72.

Niemeyer, B., \& Colley, H. (2015). Why do we need (another) special issue on gender and VET? Journal of Vocational Education and Training, 67(1), 1-10.

Palma, I., Reyes, D., \& Moreno, C. (2013). Educación sexual en Chile: Pluralismo y libertad de elección que esconde una propuesta gubernamental conservadora. Política Educativa, 49, 1424.

Romero, M., Martín, N., Castañón, S., Maquieira, V., \& Pichardo, J. I. (2005). Vivencia de la homosexualidad y supervivencia a la homofobia en las aulas. Estudio Cualitativo sobre la percepción que los adolescentes tienen sobre la homosexualidad y las situaciones de acoso que viven los adolescentes LGTB. En J. Generelo \& J. I. Pichardo (Coords.) Homofobia en el sistema Educativo. COGAM.

Rojas, M. T., Fernández, M. B., Astudillo, P., Stefoni, C., Salinas, P., \& Valdebenito, M. J. (2019). La inclusión de estudiantes LGBTI en las escuelas chilenas: entre invisibilización y reconocimiento social. Pensamiento Educativo. Revista de Investigación Educacional Latinoamericana, 56(1), 14.

Rollin, Z. (2012). Genre et sexualité dans le rapport pédagogique: Ethnographie d'un lycée « de banlieue » Genre, Sexualité et Société, 7. https://gss.revues.org/2350

Rubin, G. (1984). Thinking sex: Notes for a radical theory of the politics of sexuality. En C. Vance (Ed.) Pleasure and danger. Exploring female sexuality (pp. 143-178). Routledge \& Kegan Paul.

Salas, N., \& Salas, M. (2016). Tiza de colores: Hacia la enseñanza de la inclusión sobre diversidad sexual en la formación inicial docente. Revista Latinoamericana de Educación Inclusiva, 10(2), 7391. 
Scott, J. (1990). El género, una categoría útil para el análisis histórico. En J. Amelang \& M. Nash (Eds.), Historia y género: Las mujeres en Europa moderna (pp. 23-56). Alfons el Magnanim.

Staunston, H. (2019). Challenging gender and sexuality-based discrimination in UK schools. Young women's experiences of illegitimation and resistance. En H. Sauntson \& J. I. Kjaran (Eds.), School as queer transformative spaces (pp. 123-142). Routledge.

Stolze, B. \& Ramírez, S. (2015). Educación sexual y tradiciones pedagógicas en la formación docente. Temas de Educación, 21(1), 153-164.

Todo Mejora. (2016). Encuesta Nacional de Clima Escolar 2016. Author.

UNESCO. (2016). Abiertamente. Respuesta del sector de educación a la violencia basada en orientación sexual y la identidad/expresión de género. http://unesdoc.unesco.org/images/0024/002446/244652s.pdf

UNESCO. (2019). La pedagogía de la sexualidad. Procesos de planificación e implementación didáctica realizados por docentes en Chile a partir de las Orientaciones Técnicas Internacionales sobre Educación en Sexualidad de UNESCO. UNESCO-OREALC. http://www.codajic.org/sites/ www.codajic.org/files $/ \mathrm{La} \% 20$ pedagog $\% \mathrm{C} 3 \% \mathrm{ADa} \% 20 \mathrm{de} \% 20 \mathrm{a} \% \% 20$ sexualidad $\% 20$ Chile.pdf

Youdell, D. (2005). Sex-gender-sexuality: How sex, gender and sexuality constellations are constituted in secondary schools. Gender and Education, 17(3), 249-270

Wei, G. (2020). Teaching gender. Narrative inquiries into teachers' practical knowledge for gender equaility and social justice. En H. Sauntson \& J. I. Kjaran (Eds.), Schools as queer transformative spaces. Global narratives on sexualities and gender. Routledge.

Wittig, M. (1980). The straight mind. Feminist Issues, 1(1), 103-111.

\section{Sobre los Autores}

\section{Pablo Astudillo Lizama}

Facultad de Educación, Universidad Alberto Hurtado

pastudil@,uahurtado.cl

Doctor en Sociología de la Universidad René Descartes - Paris 5. Master en ciencias sociales, especialidad género, política y sexualidad de la Escuela de altos estudios en ciencias sociales de París, Francia. Licenciado en Sociología de la Pontificia Universidad Católica de Chile. Profesor asistente de la Facultad de Educación, Universidad Alberto Hurtado. Temas de investigación: Políticas educativas, educación sexual e inclusión de género y diversidad sexual en el sistema educativo chileno.

ORCID: 0000-0002-7424-4038

\section{Rocío Faúndez García}

Fundación Todo Mejora, Chile

rofaundezg@gmail.com

Magister en Estudios Sociales y Políticos Latinoamericanos de la Universidad Alberto Hurtado y Máster en Ciencias Políticas y Sociales de la Universidad Pompeu Fabra. Licenciada en Trabajo Social y Ciencias Políticas de la Pontificia Universidad Católica de Chile. Amplia experiencia en docencia y en estudios aplicados de ciencias sociales y políticas, con foco en políticas sociales relacionadas a niñez y adolescencia, género, inclusión en educación, participación ciudadana y política migratoria. 


\section{Sobre los Editores}

\section{Jaime Barrientos Delgado}

Facultad de Psicología, Universidad Alberto Hurtado

jbarrientos@,uahurtado.cl

Doctor en Psicología Social, Universitat de Barcelona, master en Ciencias Sociales, Universidad de Chile y Psicólogo de la Universidad Diego Portales. Profesor titular e investigador de la Facultad de Psicología, Universidad Alberto Hurtado. Temas de investigación: sexualidad, género y diversidad desde la Psicología Social. Violencia homofóbica, impacto de los prejuicios y la discriminación en la salud mental de gays, hombres y lesbianas.

ORCID: https://orcid.org/0000-0001-8497-3552

\section{María Teresa Rojas}

Facultad de Educación, Universidad Alberto Hurtado

mtrojas@,uahurtado.cl

Doctora en Ciencias de la Educación de la P. Universidad Católica de Chile y de la Universidad René Descartes - Paris 5. Licenciada en Historia y Profesora de Historia y Geografía de la Pontificia Universidad Católica de Chile. Profesora asociada de la Facultad de Educación, Universidad Alberto Hurtado. Temas de investigación: Políticas educativas y sociología de la escuela; subjetividad y decisiones de los actores escolares; análisis de la segmentación/inclusión del sistema escolar chileno desde diferentes perspectivas, entre ellas la inclusión social y la mixtura social en las escuelas, la inclusión LGTBI en contextos educativos, y la inclusión de estudiantes migrantes en escuelas municipales.

ORCID: https://orcid.org/0000-0001-9195-2688

\section{Ismael Tabilo Prieto}

Facultad de Psicología, Universidad Alberto Hurtado itabilo@,uahurtado.cl

Sociólogo de la Universidad Alberto Hurtado, Máster en Ciencias Sociales por l'École des Hautes Études en Sciences Sociales de Paris (EHESS). Académico colaborador de la Facultad de Psicología, Universidad Alberto Hurtado y de la Facultad de Psicología, Educación y Familia de la Universidad Finis Terrae. Investigador de política educativa en el Laboratorio de Investigación e Innovación en Educación para América Latina y el Caribe (SUMMA) durante la edición de este número especial. Temas de investigación: enfoque biográfico y estudios de curso de vida, sociología de la educación y el trabajo, transiciones educación-trabajo, política educativa, métodos de investigación social. ORCID: https://orcid.org/0000-0002-7501-5085

\section{Canela Bodenhofer}

SUMMA, Laboratorio de Investigación e Innovación en Educación para América Latina y el Caribe. canela.bodenhofer@summaedu.org

Socióloga de la Universidad de Chile, forma parte del Núcleo Sentipensante de Metodologías Participativas de la misma universidad. Investigadora de Política Educativa de SUMMA, Laboratorio de investigación e innovación en educación para América Latina y el Caribe. Temas de investigación: política educativa, derecho a la educación, inclusión en educación, género y educación, experiencias de actores trans y cis en la escuela, derechos humanos. 


\section{Número Especial \\ Derecho a la Educación e Inclusión Escolar de Jóvenes LGTB+ en América Latina y el Caribe}

\section{archivos analíticos de políticas educativas}

\section{(c) (†) (?)}

Los/as lectores/as pueden copiar, mostrar, distribuir, y adaptar este artículo, siempre y cuando se de crédito y atribución al autor/es y a Archivos Analíticos de Políticas Educativas, los cambios se identifican y la misma licencia se aplica al trabajo derivada. Más detalles de la licencia de Creative Commons se encuentran en https://creativecommons.org/licenses/by/4.0/. Cualquier otro uso debe ser aprobado en conjunto por el autor/es, o AAPE/EPAA. La sección en español para Sud América de AAPE/EPAA es publicada por el Mary Lou Fulton Teachers College, Arizona State University y la Universidad de San Andrés de Argentina. Los artículos que aparecen en AAPE son indexados en CIRC (Clasificación Integrada de Revistas Científicas, España) DIALNET (España), Directory of Open Access Journals, EBSCO Education Research Complete, ERIC, Education Full Text (H.W. Wilson), PubMed, QUALIS A1 (Brazil), Redalyc, SCImago Journal Rank, SCOPUS, SOCOLAR (China).

Sobre el Consejo Editorial: https://epaa.asu.edu/ojs/index.php/epaa/about/editorialTeam

Por errores y sugerencias contacte a Fischman@asu.edu

Síganos en EPAA's Facebook comunidad at https://www.facebook.com/EPAAAAPE y en Twitter feed@epaa_aape. 